\title{
GRANTS, GENDER AND GLASS CEILINGS? \\ An Analysis of ARC-Funded Archaeology Projects
}

\author{
Joann K. Bowman ${ }^{1}$ and Sean Ulm²
}

\begin{abstract}
A recent study by Smith and Burke (2006) found that barriers to women's advancement existed in Australian academic archaeology workplaces. They examined gender biases in employment and publication rates, concluding that systemic barriers exist for women in archaeology despite recent initiatives towards greater gender equity. Smith and Burke identified funding as an area of interest but made only a cursory examination of this issue. We undertook an analysis of ARC-funded archaeology Discovery Projects awarded between 2001 and 2008 to further investigate the influence of gender biases on grant funding. Results show considerable gender disparity in a number of areas, including the gender composition of grant investigators, the amount of funding awarded, the geographical focus of grants and the awarding of fellowships. Of greatest concern is an apparent correlation between the gender of successful applicants and the ratio of women to men serving on the ARC's Humanities and Creative Arts Panel responsible for the assessment of grant applications. In other words, institutional factors may be contributing to gender disparities in archaeology.
\end{abstract}

\section{Introduction}

Issues of gender and gender equity in archaeology have received increasing attention in recent decades. Gender concerns have been addressed both in terms of ways of investigating the past (e.g. papers in Balme and Beck 1995; Casey et al. 1998) and as a matter to redress within the discipline itself (e.g. Bowdler and Clune 2000; Buckley 1993; Clarke 1993; Smith and du Cros 1995; Truscott and Smith 1993; Wylie 1993; for international examples see papers in Nelson et al. 1994). Studies of gender within the discipline have focused on two main areas: women in archaeological workplaces generally (e.g. Clarke 1993; Gero 1985; Hope 1993; McGowan 1995) and women in academic institutions specifically, both as students and academics (e.g. Cusack and Campbell 1993; Hutson 2002; Webb and Frankel 1995). The disparity between the experiences of men and women in archaeological workplaces has been noted by many of these studies. Despite the proliferation of studies of gender in archaeology, gender participation rates in competitive funding for archaeological research have received little attention.

In the United States, Yellen's (1994) comparative study of National Science Foundation archaeology funding between 1978-1981 and 1989 showed persistent differences between male and female success rates, although these had narrowed between the two study periods. Yellen (1994) found that few women receiving funding for $\mathrm{PhD}$ research continued into active research

School of Social Science, The University of Queensland, Brisbane, QLD 4072, Australia joann.bowman@uqconnect.edu.au

Aboriginal and Torres Strait Islander Studies Unit, The University of Queensland, Brisbane, QLD 4072, Australia s.ulm@uq.edu.au careers and that mid-career women were less competitive than men. Of particular interest, Yellen's (1994:55-56) review of the assessment process showed that external male assessors ranked female-submitted grants lower than male-submitted grants (although external female assessors did not rank male-submitted grants lower).

Smith and Burke (2006) identified funding of archaeological research as a key area of interest in Australia, but made only a preliminary assessment of gender parity in this area. They suggested that the predominance of women in research positions within academic institutions indicated that women may have been marginalised from mainstream teaching/research academic positions or that the flexibility of research positions better complemented family commitments (Smith and Burke 2006:19). They also noted with concern, however, that application rates of female academics for Australian Research Council (ARC) grants were considerably lower than the proportion of women archaeologists employed in academic positions (Smith and Burke 2006:20).

In an analysis of ARC funding for 1996, Jayasinghe et al. (2001) argued that gender did not play a role in the peer review process and subsequent acceptance or rejection of grant applications. However, aggregated data such as those used by Jayasinghe et al. (2001) and those reported by the ARC (e.g. ARC 2005a, 2006a) on the gender breakdown of investigators on grant applications and awarded grants gives only a very general picture of gender parity in academic research funding - a more discipline-specific analysis is needed. To address this issue, a survey was undertaken of all ARC Discovery Project grants awarded under Research Fields, Courses and Disciplines (RFCD) code 4302 Archaeology and Prehistory between 2001 and 2008 (ARC 2001a, 2002a, 2003a, 2004a, 2005b, 2006b, 2007a, 2008a).

A number of questions were posed for this study:

- What is the female:male ratio among investigators on funded grants and is there a relationship between gender and name-order?

- Is there a correlation between the gender of the first-named investigator and the amount of funding awarded?

- What is the female:male ratio in grants with different geographical foci?

- Are there any differences in the female:male ratio of investigators in relation to the administering organisation of the grants?

- Is gender disparity evident in the female:male ratio among fellowship recipients?

\section{Methods}

While archaeology-related grants were awarded under other RFCD codes in the period sampled, such as Anthropology and 


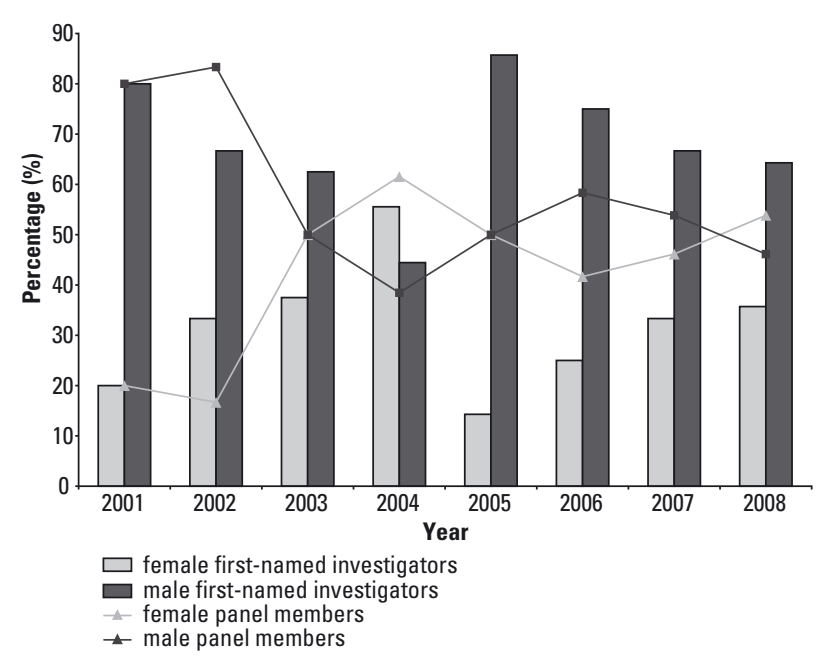

Figure 1 Comparison of first-named investigators on grants and members of the Humanities and Creative Arts Panel according to gender and year.

Geology, the sample was restricted to projects funded under the Archaeology and Prehistory RFCD code, as considerable difficulties arose in determining the archaeological relevance of projects funded under other RFCD codes. Restricting the study to the Archaeology and Prehistory RFCD code also controlled for differences in the way that grant applications were assessed. In total, 76 grants were awarded under the Archaeology and Prehistory RFCD code between 2001 and 2008, with 173 investigators named on those grants. Only successful grant applications are considered here as the ARC does not publish details of unsuccessful grants beyond aggregate data for all disciplines combined. It was initially intended to analyse ARC Linkage Projects for the same period but the sample size proved to be too small $(\mathrm{n}=15)$ for meaningful analysis.

Descriptions of successful Archaeology and Prehistory coded Discovery Project grants awarded between 2001 and 2008 published by the ARC (2001a, 2002a, 2003a, 2004a, 2005b, 2006b, $2007 \mathrm{a}, 2008 \mathrm{a})$ were reviewed in terms of the year/s funding was awarded, funded amount, administering organisation and the title of each grant. The name, gender and name-order of each investigator were also recorded. We acknowledge that the nameorder of investigators on successful grant applications may be impacted by factors other than the ranking of responsibility for individual grant projects, such as seniority, the facilities available at institutional bases or simply where investigator surnames fall in the alphabet. Investigation of the impact of these factors is beyond the scope of the current project. Gender was determined through internet searches, primarily of staff directories on university websites. In instances where the gender of an investigator could not be determined in this manner, the first-named investigator of the relevant grant was contacted for clarification. Fellowship information, including the type of fellowship funded - Australian Postdoctoral Fellowships (APD), Australian Research Fellowships (ARF), Queen Elizabeth II Fellowships (QEII) and Australian Professorial Fellowships $(\mathrm{APF})$ - and the name and gender of fellowship recipients was also recorded. Each grant was assigned a geographical area of focus (Europe, Middle East, Asia, Australasia, Oceania or Indian Ocean). The geographical area was identified from examination of the available data; some difficulties were encountered, however, as detailed information regarding the geographical focus of the grant was not always present in the published information. A significant limitation was that only the 'Summary of National/ Community Benefit' section of each successful application is made publically available by the ARC, rather than the more useful 'Summary of Project' section on the original application.

Information regarding the ARC College of Experts' Humanities and Creative Arts Panel that assesses all Archaeology and Prehistory coded grant applications was also collected (ARC 2001b, 2002b, 2003b, 2004b, 2005c, 2006c, $2007 \mathrm{~b}, 2008 \mathrm{~b}$ ). The name and gender of all panel members for each of the years sampled were recorded. As with grant investigators, the gender of the panel members was identified through internet searches.

\section{Results}

The gender proportions of named investigators for all Discovery Project grants awarded through 2001-2008 across all RFCD codes are $21.5 \%(n=3350)$ women and $78.5 \%(n=12217)$ men. In Archaeology and Prehistory coded grants, however, $28.9 \%$ $(\mathrm{n}=50)$ of named investigators were women, and $71.1 \%(\mathrm{n}=123)$ men, suggesting that funding for archaeology projects is slightly less gender-biased than the average for all successful applications. When first-named investigators are examined separately the figures are similar to those for all investigators on Archaeology and Prehistory coded grants, with $32.9 \%(n=25)$ of first-named investigators women and $67.1 \%(n=51)$ men.

\section{Humanities and Creative Arts Panel}

Comparison of the gender ratios of investigators on successful grants with the gender ratios of the Humanities and Creative Arts Panel reveals a distinct pattern (Figure 1). There is a close link between the female:male ratios of panel members and that of successful grant applicants - the only year in which there were more female- than male-headed grants (2004) was one of only two years in which the Humanities and Creative Arts Panel comprised a female majority. This correlation between the composition of the panel and the gender ratios of successful grant applicants is evident for both first-named investigators and overall numbers of successful male and female applicants. The correlation is, however, more pronounced with first-named investigators. This suggests that the decisions of panel members may be influenced by the gender of the investigators listed on a grant application, particularly the first-named investigator that panel members are more likely to support grants headed by members of the same gender. As there are generally more men than women on the panel, this results in a tendency towards more male-headed grants receiving funding.

\section{Name-Order Position}

The data show that women are not proportionally over-represented in lower-ranked name-order positions (i.e. listed after the firstnamed investigator), with a female:male ratio of approximately 1:3 on average. To investigate this further, the ratios of male and female investigators on teams (projects with more than one named investigator) were calculated. This reveals that male-headed teams have a slightly higher proportion of male subsequent members than the average. When a man is heading the grant, women make up $22.5 \%(n=16)$ of lower-ranked investigators and men 


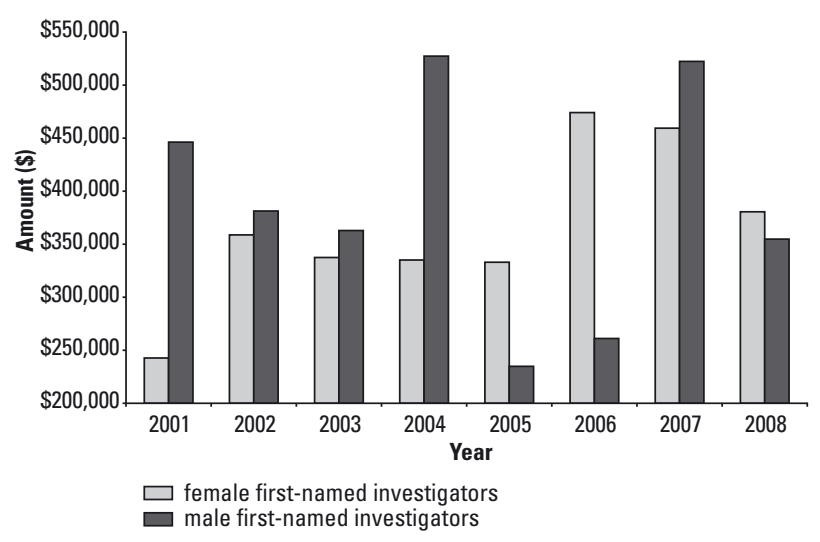

Figure 2 Average amount of funding awarded to each grant according to gender of first-named investigator and year.

$77.5 \%(\mathrm{n}=55)$. Female-headed grants, however, reflect greater gender equity in the numbers of men and women lower-ranked investigators - women comprised $34.6 \%(\mathrm{n}=9)$ of lower-ranked investigators and men $65.4 \%(n=17)$ over all years, with equal proportions of men and women for years 2002, 2003, 2004 and 2008 (2001 and 2005 had no female-headed grants of more than one investigator while 2006 and 2007 had only one).

This suggests that male first-named investigators are more likely to favour other men, while females are more likely to include an equal number of men and women on the grant. This may be a reason for the low numbers of women on grants - there are more men heading grants who, in choosing not to include women colleagues as research collaborators on those grants, are contributing to the gender disparity in grant composition. This is supported by employment data for academic archaeology positions in Australia that showed the proportion of positions filled by women to be significantly higher than the proportion of women on grants - women held $41 \%$ of academic archaeology positions in 2006 (Smith and Burke 2006:15) but, as stated above, filled fewer than $30 \%$ of positions on grants. Furthermore, Smith and Burke (2006) noted that while women filled $41 \%$ of positions overall they held $61 \%$ of research positions. The much lower numbers of women on grants indicates that the high proportion of women employed in research-focused positions is not translated into a large female presence in ARC-funded grants. This suggests that the gender ratios on ARC-funded grants are more disparate than would be expected if gender were not influencing the success of grant applications. However, discipline-specific data regarding application and success rates are not available to test this hypothesis.

\section{Funding}

For the period of analysis, female- and male-headed grants received equal amounts of funding on average (female-headed grants received $\$ 380,105$ on average and male-headed grants $\$ 375,046$ on average). A few large grants headed by women investigators in recent years (2005-2007) may have skewed these figures, however, as previous years show a pattern of consistently less funding for female- compared to male-headed projects (Figure 2). However, it is possible that this recent increase in

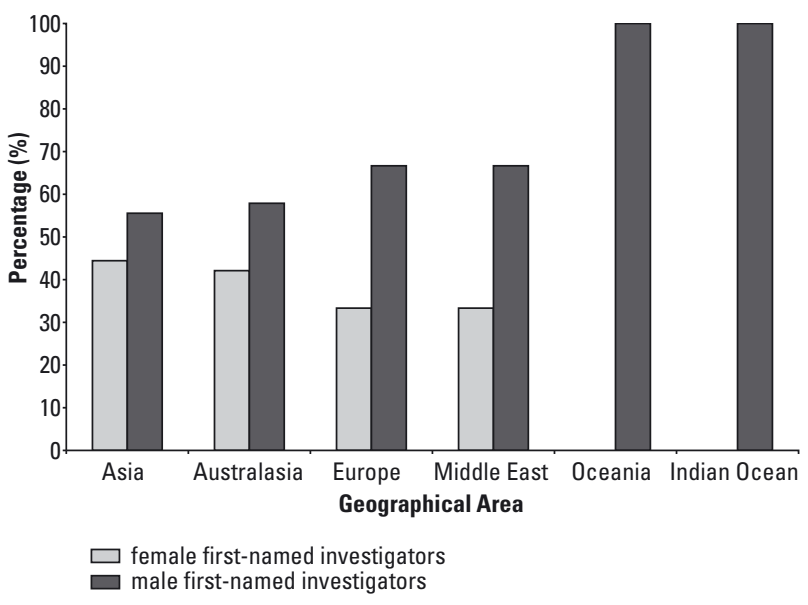

Figure 3 First-named investigators on grants according to gender and geographical foci, 2001-2008.

the amount of funding awarded to female-headed grants may, in fact, represent a shift in the trend rather than an anomaly. The amount of funding received by men and women does not show the same correlation with the gender composition of the Humanities and Creative Arts Panel that is evident in the gender composition of named investigators. This may suggest that the gender composition of grant applications is not as influential with regards to the amount of funding awarded as it is in regards to the likelihood of the grant being funded at all - in other words, the amount of funding awarded to female- and male-headed grants is not a factor of the gender ratios of those determining the amount of funding to be awarded. The disparity evident along gender lines in the amount of funding awarded in earlier years may be due to the type of research being conducted. There is a widely-held perception that men conduct more field-based research than women (Gero 1985; Phillips 1998; Yellen 1983:6162; cf. Yellen 1994:54). If true, this may influence how funding was apportioned between men and women, as field-based projects generally require greater resources.

\section{Geographical Area}

In all geographical categories there are fewer women than men first-named investigators (Figure 3). This is particularly pronounced in Oceania-based projects, where there are no projects headed by female investigators (note that the Indian Ocean category comprises a single grant). For grants focused on Europe and the Middle East there are almost twice as many grants headed by men as by women (see also Webb and Frankel 1995). Women not only hold fewer first-named positions, but are proportionally less likely than men to be firstnamed investigators in terms of the overall numbers of women and men investigators on grants in each geographical foci. For example, men comprise $60 \%$ of named investigators, but $67 \%$ of first-named investigators, on projects in Europe, while women represent $40 \%$ of named investigators but only $33 \%$ of first-named investigators. The exception to this is Asia, where women represent $27.1 \%$ of named investigators but $44.4 \%$ of first-named investigators. This may indicate a higher level of success for female researchers in this area of study compared to others. 


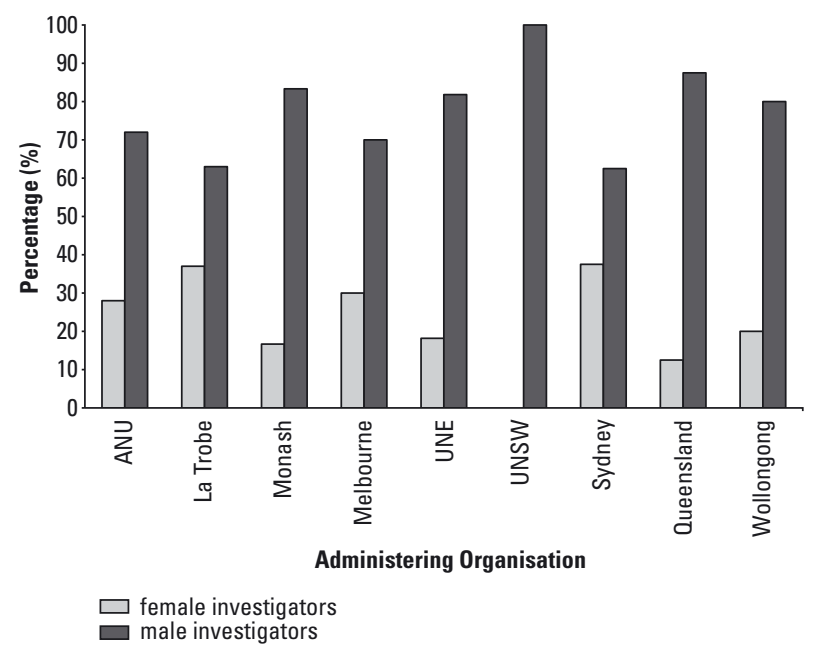

Figure 4 All named investigators on grants according to gender and the administering organisation of the grant, 2001-2008.

\section{Administering Organisation}

Figure 4 shows the proportions of all female and male investigators by administering organisation. Female:male ratios for grants administered by the Australian National University (ANU), La Trobe, University of Melbourne and University of Sydney are broadly similar to the overall proportions of $28.9 \%(n=50)$ for female investigators and $71.1 \%(n=123)$ for male investigators. However, the data for the remaining five universities administering grants during the period of analysis show considerable gender disparities. University of New South Wales (UNSW) administered only one grant and Monash University and the University of Wollongong administered only three grants each during this time and, therefore, the figures relating to these institutions do not necessarily illustrate any gender disparity. However, the University of Queensland and the University of New England (UNE) both show greater disparity in female:male ratios than the average.

Interestingly, while grants administered by La Trobe show a gender composition for all investigators in line with the average, the female:male ratio of first-named investigators is reversed, with $55.6 \%$ of first-named investigators women and $44.4 \%$ men. A similar pattern exists in grants administered by the University of Sydney, where the female:male ratio for first-named investigators shows greater parity than that of all investigators on University of Sydney administered grants $(47.6 \%$ women and $52.4 \%$ men for first-named investigators compared to $37.5 \%$ women and $62.5 \%$ men for all investigators). These figures may reflect differences in the work environments at these institutions - institutions that show higher proportions of female first-named investigators may have less 'chilly climates' (Wylie 1993) for women employees than others.

The higher proportions of female first-named investigators evident in some administering organisations may also be due to higher numbers of women being employed in more advanced positions at these institutions. This is particularly evident at the University of Sydney, which, based on data reported by Smith and Burke (2006:14-15), has a large proportion of women employed in high-level positions. Further comparison with the employment data reported in Smith and Burke (2006) is

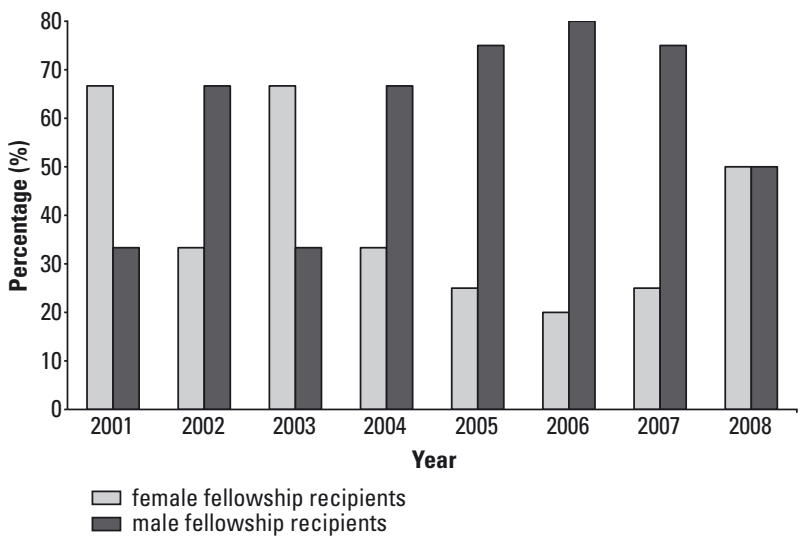

Figure 5 All fellowship recipients according to gender and year.

useful, although, as this information only concerns employment numbers as at 2006, comparisons with the 2001-2008 aggregated grant data must be tentative. Grants administered by University of Sydney show female:male ratios for all investigators in line with the employment figures provided by Smith and Burke (2006), with La Trobe, University of Melbourne and UNE also showing ratios generally similar to their employment ratios. ANU and the University of Queensland, however, have a lower proportion of women on grants compared to the proportion of women employed in archaeology positions. Excepting UNE, the female:male ratios on grants are lower than the female:male ratios for each administering organisation.

\section{Fellowships}

Women constitute 37.5\% $(n=15)$ and men $62.5 \%(n=25)$ of fellowship recipients in the period analysed. This figure shows greater parity than both the overall proportion of women on Archaeology and Prehistory-coded grants (28.9\%) and the proportion of female first-named investigators $(32.9 \%)$. When the fellowship represents the entire grant (i.e. when the fellowship recipient is the sole investigator listed on the grant) the ratio of women to men is closer to equal, with women at $40.9 \%(\mathrm{n}=9)$ and men $59.1 \%(\mathrm{n}=13)$. This suggests that ability to attract funding through fellowships is not greatly influenced by the gender of the applicant. Although 2008 shows equal numbers of male and female fellowship recipients, major disparities in the female:male ratios for fellowship recipients is evident in previous years, though the overall number of fellowship recipients in 2001-2003 is very low (Figure 5). The 2005-2007 pattern may be associated with the general decrease in women investigators in these years, and also with the accompanying decrease in the proportion of women on the Humanities and Creative Arts Panel assessing the grant applications (see Figure 1).

Where fellowships are part of a grant that is headed by someone other than the fellowship recipient, female fellowship recipients are more than three times as likely to be listed as investigators on female-headed grants $(57.1 \%)$ than male-headed grants $(16.7 \%)$. This pattern may reflect the low numbers of female investigators generally (and female fellowship recipients in particular) or indicate that both male and female first-named investigators tend to favour same-gender colleagues. However, given that first-named investigators have a decisive influence on 
the appointment of fellowship recipients, the data do indicate that male first-named investigators are more likely to favour same-gender colleagues than female first-named investigators.

\section{Discussion}

Results demonstrate considerable gender disparities in ARC funding of archaeology projects. As discipline-specific information on the gender ratios of all applicants (i.e. information relating to both successful and unsuccessful applications) is not publicly available, the influence of gender on either grant application or success rates cannot be determined (cf. Yellen 1994). However, the consistent correlation between the gender ratios of first-named investigators and that of the Humanities and Creative Arts Panel members assessing the applications provides strong circumstantial evidence that gender plays a role in the selection process for ARC funding of archaeology projects. The gender of the first-named investigator also appears, to some degree, to be a determining factor in the appointment of subsequent investigators, with first-named investigators tending to favour colleagues of the same gender. However, while the proportion of women on successful grants is low overall, particularly on those headed by men, they are not marginalised to lower-ranked name-order positions.

Fellowships are one of the main sources of funding for those pursuing research careers in archaeology. As there is a dominance of women employed in research-based positions within archaeology departments in Australian universities (Smith and Burke 2006:15), it would be expected that, all things being equal, the gender ratios of fellowship recipients would reflect this female majority. However, this is clearly not the case - there is a distinct pattern of gender disparity where men are more likely to receive fellowships than women. The situation, then, seems to be one where a majority of the funding is received by a minority of the researchers. Fellowships are a category of funding often sought by those in the initial stages of their careers. The disparity along gender lines in this early-career funding category means that women are disadvantaged early on in their academic lives. The cumulative effects of such gender discrimination contribute to the glass ceiling phenomenon with fewer women progressing to more senior positions.

The findings presented here are in disagreement with the study by Jayasinghe et al. (2001) that claimed the peer review process for ARC funding was not influenced by the gender of the participants. The data exhibit a clear correlation between the gender ratios of grant applicants and those of the Humanities and Creative Arts Panel. This phenomenon may be restricted to archaeology-related grants, however, given the similarity of the gender ratios for archaeology grants to the overall figures reported by the ARC, it is likely that the correlation is more widespread. In spite of Jayasinge et al.'s (2001) claims, it is not unexpected that the Humanities and Creative Arts Panel exerts significant influence over the awarding of grants. Given the push in recent decades towards greater gender equity, however, it is surprising that such a pronounced link should seemingly exist between the gender composition of the Humanities and Creative Arts Panel and that of the successful recipients of the grants awarded each year. We note that the lower representation of women on the Humanities and Creative Arts Panel after 2004 may be related to a wider decline of women in leadership positions in Australia identified in a recent study by the Australian Equal Opportunity for Women in the Workplace Agency (2008).

The nature of the work environment in which the project is being undertaken is also a major factor in the gender parity of grant funding. A work environment that discriminates against women may be one of the reasons for the disproportionately small number of women on grants when compared to the number of women employed in the institution administering those grants. Wylie (1993) has identified four practices stereotyping, devaluation, exclusion and revictimisation - that contribute to what she has termed a 'chilly climate' for women in academic settings. These practices, if present in an academic workplace, may affect the likelihood of women's participation on grants administered by that institution. Perceptions (and misperceptions) about the competitiveness of women in attracting funding, held both by women themselves and the academy generally, may be a significant factor in the low application rates of women (Smith and Burke 2006:20). Women may feel discouraged from applying for funding if the perception exists that they are less likely to be successful than their male colleagues. Investigators - both male and female - generally tend to favour colleagues of the same gender. Reasons for this are likely to be numerous, with not only conscious and targeted discrimination, but also unconscious discrimination against women playing a role (Wylie 1993). For example, people may feel more comfortable working with colleagues of the same gender.

\section{Conclusion}

This study documents gender disparities in ARC-funded archaeology Discovery Projects awarded between 2001 and 2008. Gender disparities are evident in the gender composition of grant investigators, the amount of funding awarded, the geographical focus of grants and the awarding of fellowships. A possible link is identified between the gender of successful applicants and the proportion of women and men on the ARC's Humanities and Creative Arts Panel.

Success in attracting funding is an important factor in an academic archaeologist's career, particularly as it impacts on employment and promotion prospects. Funding also shapes our understanding of the archaeological record as it determines who conducts research into what and where, as well as when and how, that research is undertaken. Clearly, gender disparities in the allocation of ARC funding have wide-ranging repercussions for the practice of archaeology in Australia and warrant ongoing attention.

\section{Acknowledgements}

This research was undertaken in the Aboriginal and Torres Strait Islander Studies Unit, The University of Queensland. Thanks to Alison Betts, Richard Cosgrove, Michael Spriggs, Robin Torrence and Marshall Weisler for confirming various facts. Thanks also to Jenny Kahn, Claire Smith and Kate Barney for support and advice, to Heather Burke for invaluable comments on an early $\mathrm{draft}$, and to the referees for constructive and useful direction.

\section{References}

Australian Research Council 2001a Successful 2002 Discovery Project Grants by RFCD. Retrieved 16 March 2007 from http://www.arc.gov.au/pdf/2002_dp_ rfcd.pdf. 
Australian Research Council 2001b Annual Report 2000-01. Canberra: AusInfo. Australian Research Council 2002a Successful 2003 Discovery Project Grants by RFCD. Retrieved 16 March 2007 from http://www.arc.gov.au/pdf/2003_DP_ RFCD.pdf.

Australian Research Council 2002b Annual Report 2001-02. Canberra: AusInfo. Australian Research Council 2003a Successful 2004 Discovery Projects by RFCD

Code. Retrieved 16 March 2007 from http://www.arc.gov.au/pdf/DP2004 Project_details_by_RFCD-Nov.pdf.

Australian Research Council 2003b Annual Report 2002-03. Canberra: AusInfo. Australian Research Council 2004a Successful 2005 Discovery Projects by RFCD Code. Retrieved 16 March 2007 from http://www.arc.gov.au/pdf/dp05_rfcd.pdf. Australian Research Council 2004b Annual Report 2003-04. Canberra: AusInfo. Australian Research Council 2005a Discovery Projects Selection Report for Funding Commencing in 2006. Retrieved 16 March 2007 from http://www.arc.gov.au/ funded_grants/DP06_SelectionReport.htm.

Australian Research Council 2005b Summary of Discovery Projects Applications for Funding to Commence in 2006. Retrieved 16 March 2007 from http://www.arc. gov.au/pdf/DP06_RFCD.pdf.

Australian Research Council 2005c Annual Report 2004-05. Canberra: AusInfo. Australian Research Council 2006a Discovery Projects Selection Report for Funding Commencing in 2007. Retrieved 16 March 2007 from http://www.arc.gov.au/ funded_grants/DP07_Selection_Rpt.htm.

Australian Research Council 2006b Summary of Discovery Projects Proposals by Primary Class Code for Funding to Commence in 2007. Retrieved 16 March 2007 from http://www.arc.gov.au/pdf/DP07/DP07_RFCD.pdf.

Australian Research Council 2006c Annual Report 2005-06. Canberra: AusInfo. Australian Research Council 2007a Summary of Discovery Projects Proposals by Primary Class Code for Funding to Commence in 2008. Retrieved 15 November 2007 from http://www.arc.gov.au/pdf/DP08/DP08_RFCD.pdf.

Australian Research Council 2007b Annual Report 2006-07. Canberra: AusInfo. Australian Research Council 2008a Summary of Discovery Projects Proposals by Primary Class Code for Funding to Commence in 2009. Retrieved 1 December 2008 from http://www.arc.gov.au/pdf/DP09/DP09_RFCD.pdf.

Australian Research Council 2008b Annual Report 2007-08. Canberra: AusInfo. Balme, J. and W. Beck (eds) 1995 Gendered Archaeology: The Second Australian Women in Archaeology Conference. Research Papers in Archaeology and Natural History 26. Canberra: Archaeology and Natural History Publications, Research School of Pacific Studies, Australian National University.

Bowdler, S. and G. Clune 2000 That shadowy band: The role of women in the development of Australian archaeology. Australian Archaeology 50:27-35.

Buckley, K. 1993 Cultural resource management and gender issues. In H. du Cros and L. Smith (eds), Women in Archaeology: A Feminist Critique, pp.173-174. Occasional Papers in Prehistory 23. Canberra: Department of Prehistory, Research School of Pacific Studies, Australian National University.

Casey, M., D. Donlon, J. Hope and S. Wellfare (eds) 1998 Redefining Archaeology: Feminist Perspectives. Research Papers in Archaeology and Natural History 29. Canberra: Archaeology and Natural History Publications, Research School of Pacific Studies, Australian National University.

Clarke, A. 1993 Cultural resource management (CRM) as archaeological housework: Confining women to the ghetto of management. In H. du Cros and L. Smith (eds), Women in Archaeology: A Feminist Critique, pp.191-194. Occasional Papers in Prehistory 23. Canberra: Department of Prehistory, Research School of Pacific Studies, Australian National University.

Cusack, C.M. and G. Campbell 1993 Women and postgraduate education: Problems and predictions. In H. du Cros and L. Smith (eds), Women in Archaeology: A Feminist Critique, pp.232-236. Occasional Papers in Prehistory 23. Canberra: Department of Prehistory, Research School of Pacific Studies, Australian National University.
Equal Opportunity for Women in the Workplace Agency 2008 EOWA2008: Australian Census of Women in Leadership. North Sydney: Equal Opportunity for Women in the Workplace Agency.

Gero, J.M. 1985 Sociopolitics and the woman-at-home ideology. American Antiquity 50(2):342-350.

Hope, J. 1993 Double bind: Women archaeologists in the New South Wales National Parks and Wildlife Service. In H. du Cros and L. Smith (eds), Women in Archaeology: A Feminist Critique, pp.175-190. Occasional Papers in Prehistory 23. Canberra: Department of Prehistory, Research School of Pacific Studies, Australian National University.

Hutson, S.R. 2002 Gendered citation practices in American Antiquity and other archaeology journals. American Antiquity 67(2):331-342.

Jayasinghe, U.W., H.W. Marsh and N. Bond 2001 Peer review in the funding of research in higher education: The Australian experience. Educational Evaluation and Policy Analysis 23(4):343-364.

McGowan, A. 1995 Working lives: Career prospects and aspirations of men and women cultural resource managers in Tasmania. In J. Balme and W. Beck (eds), Gendered Archaeology: The Second Australian Women in Archaeology Conference, pp.28-33. Research Papers in Archaeology and Natural History 26. Canberra: Archaeology and Natural History Publications, Research School of Pacific Studies, Australian National University.

Nelson, M.C., S.M. Nelson and A. Wylie (eds) 1994 Equity Issues for Women in Archaeology. Archeological Papers of the American Anthropological Association Number 5. Arlington, VA: American Anthropological Association.

Phillips, C. 1998 Answering the Old Boys' Club: Developing support systems for women archaeologists. In M. Casey, D. Donlon, J. Hope and S. Wellfare (eds), Redefining Archaeology: Feminist Perspectives, pp.63-67. Research Papers in Archaeology and Natural History 29. Canberra: Archaeology and Natural History Publications, Research School of Pacific Studies, Australian National University.

Smith, C. and H. Burke 2006 Glass ceilings, glass parasols and Australian academic archaeology. Australian Archaeology 62:13-25.

Smith, L. and H. du Cros 1995 Reflections on women in archaeology. In J. Balme and W. Beck (eds), Gendered Archaeology: The Second Australian Women in Archaeology Conference, pp.7-27. Research Papers in Archaeology and Natural History 26. Canberra: Archaeology and Natural History Publications, Research School of Pacific Studies, Australian National University.

Truscott, M.C. and L. Smith 1993 Women's roles in the archaeological workplace. In H. du Cros and L. Smith (eds), Women in Archaeology: A Feminist Critique, pp.217-221. Occasional Papers in Prehistory 23. Canberra: Department of Prehistory, Research School of Pacific Studies, Australian National University.

Webb, J.M. and D. Frankel 1995 This fair paper, this most goodly book: Gender and international scholarship in Cypriot archaeology 1920-1991. In J. Balme and W. Beck (eds), Gendered Archaeology: The Second Australian Women in Archaeology Conference, pp.34-42. Research Papers in Archaeology and Natural History 26. Canberra: Archaeology and Natural History Publications, Research School of Pacific Studies, Australian National University.

Wylie, A. 1993 Workplace issues for women in archaeology: The chilly climate. In H. du Cros and L. Smith (eds), Women in Archaeology: A Feminist Critique, pp.245-258. Occasional Papers in Prehistory 23. Canberra: Department of Prehistory, Research School of Pacific Studies, Australian National University.

Yellen, J. 1983 Women, archaeology, and the National Science Foundation. In J. Gero, D. Lacy and M.L. Blakey (eds), The Socio-Politics of Archaeology, pp.5965. Anthropology Research Report 23. Amherst: University of Massachusetts.

Yellen, J.E. 1994 Women, archaeology, and the National Science Foundation: An analysis of fiscal year 1989 data. In M.C. Nelson, S.M. Nelson and A. Wylie (eds), Equity Issues for Women in Archaeology, pp.53-57. Archeological Papers of the American Anthropological Association Number 5. Arlington, VA: American Anthropological Association. 